\title{
Learning from First-generation Qualitative Approaches in the IS Discipline \\ An Evolutionary View and Some Implications for Authors and Evaluators (Part 1/2)
}

Sarker, Suprateek; Xiao, Xiao; Beaulieu, Tanya; Lee, Allen S.

Document Version

Final published version

Published in:

Journal of the Association for Information Systems

DOI:

$10.17705 / 1$ jais.00508

Publication date:

2018

License

Unspecified

Citation for published version (APA):

Sarker, S., Xiao, X., Beaulieu, T., \& Lee, A. S. (2018). Learning from First-generation Qualitative Approaches in the IS Discipline: An Evolutionary View and Some Implications for Authors and Evaluators (Part 1/2). Journal of the Association for Information Systems, 19(8), 752-774. https://doi.org/10.17705/1jais.00508

Link to publication in CBS Research Portal

\section{General rights}

Copyright and moral rights for the publications made accessible in the public portal are retained by the authors and/or other copyright owners and it is a condition of accessing publications that users recognise and abide by the legal requirements associated with these rights.

\section{Take down policy}

If you believe that this document breaches copyright please contact us (research.lib@cbs.dk) providing details, and we will remove access to the work immediately and investigate your claim.

Download date: 26. Apr. 2023
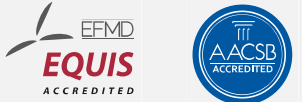


\title{
Learning from First-generation Qualitative Approaches in the IS Discipline: An Evolutionary View and Some Implications for Authors and Evaluators (Part 1/2)
}

\section{Suprateek Sarker, Kiao Kiao, Tanya Beaulieu, and Allen S. Lee}

\author{
Journal article (publisher's version)
}

\section{Please cite this article as:}

Sarker, S., Xiao, X., Beaulieu, T., \& Lee, A. S. (2018). Learning from First-generation Qualitative Approaches in the IS Discipline: An Evolutionary View and Some Implications for Authors and Evaluators (Part 1/2). Journal of the Association for Information Systems, 19(8), 752-774. https://doi.org/10.17705/1jais.00508

\section{DOl: 10.17705/ljais.00508}

Uploaded in accordance with AIS' Green Open Access Policy:

https://aisnet.org/page/PoliciesGuidelines

Uploaded to CBS Research Portal: December २०1९ 


\title{
Learning from First-Generation Qualitative Approaches in the IS Discipline: An Evolutionary View and Some Implications for Authors and Evaluators (PART 1/2)
}

\author{
Suprateek Sarker ${ }^{1}$, Xiao Xiao ${ }^{2}$, Tanya Beaulieu ${ }^{3}$, Allen S. Lee ${ }^{4}$ \\ ${ }^{1}$ University of Virginia, suprateek.sarker@comm.virginia.edu \\ ${ }^{2}$ Copenhagen Business School, Denmark, xx.digi@cbs.dk \\ ${ }^{3}$ Utah State University, tanya.beaulieu@usu.edu \\ ${ }^{4}$ Virginia Commonwealth University, aslee@vcu.edu
}

Abstract

\begin{abstract}
Qualitative research in the information systems (IS) discipline has come a long way, from being dismissed as "exploratory research" or "preresearch," not worthy of being featured in "scientific" and authoritative journals in the discipline, to a state where such research is seen as legitimate and even welcome scholarship within much of the mainstream IS research community. Despite these very positive developments in line with the value of pluralism that our discipline has embraced, and the gradual inclusion of qualitative work in high-profile mainstream outlets, recent editorials have expressed concerns regarding the research community's lack of awareness about the diverse nature of qualitative research and the apparent confusion regarding how these diverse approaches are different. Such confusion has led to a mismatch between the methodology-related expectations of evaluators and the methodological description provided by the authors (Conboy et al. 2012; Sarker et al. 2013a). To help make sense of the situation, in this editorial, we offer a critical commentary on the arena of qualitative research in the IS discipline. In viewing the adoption of qualitative research in the IS discipline as an evolutionary process, by highlighting key differences among various types of qualitative inquiry, and by drawing attention to lessons learned from the firstgeneration of qualitative approaches adopted in the IS discipline, we offer a number of implications for both authors and evaluators of qualitative manuscripts.
\end{abstract}

Keywords: Qualitative Research, Research Genres, Case Study Research, Positivism, Interpretivism, Methodology Evolution, IS Discipline.

Carol Saunders was the accepting senior editor.

\section{Introduction}

Qualitative research within the information systems (IS) discipline has a long and storied history, with changing perceptions regarding its importance and status within the discipline over time. While qualitative work is now generally viewed as "real" research, such acceptance has not always been the case. Decades of sustained effort and the dedication of several IS scholars-including but not limited to qualitative researchers-led first to accommodation, and then to the embracing of qualitative research by the mainstream IS research community. Reflecting this broad acceptance, in a recent editorial, Sarker, Xiao, \& Beaulieu (2013) observed a "steady increase" in the 
number and variety of qualitative research articles published across top IS journals. Despite the gradual acceptance and the emerging variety evident in qualitative studies, and the pronouncements of scholars in reference disciplines that qualitative research is not a "monolith" (Gubrium \& Holstein, 1997) and that it should not be constrained to a given predetermined style (Bansal \& Corley, 2011), many IS scholars nevertheless fail to acknowledge the existence and value of diversity in qualitative research (e.g., Conboy, Fitzgerald, \& Mathiassen, 2012). Furthermore, many scholars do not appear to consistently enact the understanding that each type or form of qualitative study needs to have internal "consistency" or "coherence" (i.e., an alignment between various elements of a qualitative study), and that the criteria of quality relevant to each type of qualitative research can be very different. We seek to address these issues of variety and internal consistency because confusion regarding these key characteristics of qualitative research can lead to: (a) authors not conducting and reporting on their research appropriately; (b) manuscripts being criticized/dismissed based on inapplicable methodological grounds; and (c) the publication of articles that are not logically coherent methodologically, and hence not credible to the perceptive reader.

To motivate our commentary, we begin by sensitizing readers to the basic issues introduced above by posing two questions with respect to conducting or reviewing qualitative research: (1) What criteria or values should we hold dear (or sacred) when conducting or evaluating a qualitative study? (2) As authors, wellmeaning colleagues, reviewers, and editors, what methodological references do we (or would we) utilize ourselves or suggest to other authors?

- We expect that many members of the IS research community, whether they consider themselves "qualitative researchers" or whether they occasionally undertake or evaluate such work, would answer the first question, concerning what criteria they hold dear, by mentioning a certain subset of criteria (perhaps, selected from: internal validity, construct validity, reliability, lack of bias, authenticity, rich descriptions, transparency, theoretical saturation, contextualization, plausibility, criticality, hermeneutic circle, systematic sampling, findings resonant with the stakeholders, and generalizability/transferability). ${ }^{1}$ With regard to the second question, concerning

\footnotetext{
${ }^{1}$ Some scholars do argue against having any explicit criteria for qualitative research, since they believe that such criteria fail to capture the spirit of qualitative research. However, criteria-ology has not been abandoned with respect to qualitative research because leading scholars believe that authors and evaluators do have implicit criteria-in-use, and in the interest of transparency and fairness of the evaluation
}

methodological references, many members of our research community may choose one or more of the following: Yin's Case Study Research (1994), or some later edition of the book, Klein and Myers (1999), Galliers and Land (1987), Benbasat, Goldstein, and Mead (1987), Lee (1989), Eisenhardt (1989), Miles and Huberman (1984), Walsham (1995a, 2006), Strauss and Corbin (1998), Glaser and Strauss (1967), Urquhart, Lehmann, and Myers (2010), Dubé and Paré (2003), Myers and Avison (2002), and GoldenBiddle and Locke (1993). ${ }^{2}$ However, our answer to both questions above is simply-it depends on the nature of the study.

- We submit that many scholars (both authors and reviewers) in the IS discipline continue to treat qualitative research as a homogeneous body. For instance, considering a "case study" to be a synonym for an "interpretive study" (Conboy et al., 2012) despite a number of clarifications in the literature. ${ }^{3}$ This blurring of differences among varying types of qualitative research, we believe, leads scholars to privilege, whether implicitly or explicitly, certain criteria and/or methodological references based on their personal scholarly viewpoint or even arbitrary preference, which makes fair evaluation extremely difficult, and poses a huge challenge in conducting, presenting, and justifying one's work (e.g., Gubrium \& Holstein, 1997).

- In this two-part editorial, we provide a critical commentary on the arena of qualitative research in the IS discipline, directed primarily to mainstream researchers who regularly or even occasionally utilize qualitative approaches in their work, or evaluate (i.e., review or edit) such work. To do so, we review the evolution of some of the wellestablished, "first-generation," qualitative research approaches used in the discipline. We use the term "first-generation" to refer to those qualitative approaches that have long been established within the discipline. These include exploratory case study, positivist case study, intepretive case study, grounded theory methodology, ethnography, and hermeneutics. Some approaches - e.g., action research (AR) - might also be considered in the first-generation set; however, due to the distinct nature of AR (e.g., need for interventions), and the fact that AR studies may also involve quantitative

process, the use of explicitly socially shared (if not universally accepted) criteria is justified.

${ }^{2}$ We do not imply that the criteria and the references listed here represent a comprehensive set.

3 For many scholars, qualitative research relates to interpretive and inductive work, where the meanings of both terms — "inductive" and "interpretive"-remain unclear. 
analysis, we do not consider them specifically in our analysis at this time.

- Our objective is twofold: (1) to offer an understanding of why mismatch of methodological expectations might occur-where this understanding is based on variations of fundamental dimensions, which we conceptualize as nature of data, nature of theory, nature of analysis, and nature of claims made (Part 1 of this editorial); and (2) to provide a path forward, drawing on empirically based lessons learned from existing patterns of practice involving first-generation qualitative research approaches (Part 2 of this editorial).

- We refer to existing qualitative research approaches as first-generation in order to emphasize that the qualitative approaches being utilized in the discipline are not fixed, but in a perpetual state of evolution and development, and that they constitute a foundation for newer qualitative research approaches being introduced and those to come. Indeed, we adopt the metaphor of an "s-curve" 4 in which such development passes through an initiation stage, a contagion stage, a control stage, and a maturation stage where firstgeneration qualitative research approaches merely represent an initial s-curve. Our hope is that the lessons learned and documented in this paper regarding the s-curve traveled by the firstgeneration of qualitative research approaches will facilitate the traversing of similar evolutionary paths by future generations of qualitative research approaches.

- Part 1 of this editorial is organized as follows. First, we describe the evolutionary path through which qualitative research has been adopted within the discipline; second, we characterize, in the form of "impressionist paintings," ${ }^{5}$ certain groupings of first-generation qualitative research approaches as practiced by IS researchers; third, we highlight the different criteria that may be appropriate for each grouping; and finally, we conclude Part 1 by drawing lessons learned from the study of firstgeneration approaches to inform how we may move forward. In Part 2 of this editorial, based on the implications from Part 1, we begin by examining the literature in four leading mainstream IS journals for evidence regarding the recognition of different genres and the internal coherence within each genre. Using examples, we offer some insights into the state

\footnotetext{
${ }^{4}$ The different stages have, in part, been inspired by Gibson and Nolan's (1974) description of the stages of EDP growth. ${ }^{5}$ We deliberately use the metaphor of "impressionist paintings," subscribing to the ontological stance that multiple realities exist, not only in what we as researchers observe, but also in what we as researchers do. We suggest that different artists looking at the same landscape will
}

of qualitative research in the IS discipline, and thereafter, some guidance for authors and reviewers/editors.

\section{Evolution of Qualitative Research in the IS Discipline}

To understand the evolutionary path of qualitative research, we offer a reconstruction of how the state of qualitative research methodologies has evolved (and continues to evolve) within the IS community. We do not intend it to be an objective historical account but rather an imaginative interpretation (e.g., Boland, 1991) that captures the essence of the evolution. In order to enable this storytelling, and to understand how qualitative research has developed within the discipline, we conceptualize qualitative research as an innovation in a social system (i.e., the IS discipline), and describe the evolution process using the stages of an s-curve.

In the initiation stage, qualitative research was largely unwelcome, particularly in the non-European "mainstream" outlets of the discipline. In this era, quantitative researchers enacted a "supremacist" view (Fitzgerald \& Howcroft, 1998) that dominated the methodological discourse in the discipline and its prestigious mainstream publication outlets. Many qualitative researchers enacted an "isolationist" view (Fitzgerald \& Howcroft, 1998), forming their own subcommunities, conferences, and journals, and engaging in local conversations that the mainstream was largely unaware of or paid no attention to. Others led the struggle to legitimize (in the eyes of the "mainstream") this form of research, by establishing the "scientific" nature of case research (Lee, 1989; Markus, 1983), by championing the emergence of interpretive research (Walsham, 1995b), by utilizing the rhetoric of "diversity" (Robey, 1996), by making qualitative research methodologies more accessible and understandable to mainstream audiences, and by arguing for the virtues of methodological "pluralism" in the research community (Fitzgerald \& Howcroft, 1998; Hirschheim, 1992).

The subsequent transition to the contagion stage involved qualitative research being accepted as a legitimate alternate form of research, which was fueled by the rhetoric of "exploration" (e.g., Walsham, 1995a). The underlying idea was that there are many ill-understood IS phenomena not captured by earlier theories, and that there can be no progress unless a fresh round of exploration using flexible and primarily

render different impressionist paintings of the same landscape, and at the same time, different viewers of the same impressionist painting can (and perhaps even should) construe different landscapes. Regardless, the gist of the two issues and our treatment of them will either remain largely the same or be readily translatable into the varying perspectives. 
inductive approaches is undertaken by researchers. This era brought a mindset of openness to qualitative studies. The consequence was a proliferation of case studies, many in leading outlets. However, such studies typically used obligatory citations (e.g., Benbasat et al., 1987; Eisenhardt, 1989; Lee, 1989; Walsham, 1993; Yin, 1994), sometimes appropriately but at other times merely to create the appearance of methodological rigor. Indeed, Dubé \& Paré (2003) observed that much of the qualitative research they reviewed did not actually adhere to the supposed methodological guidelines prescribed in the literature.

As in other instances of diffusion of innovation, eventually the IS research community had to selfcorrect the degree of enthusiastic openness to qualitative research, and this signaled the gradual end of the free-for-all era, and the coming of the control stage. "Method talk" (Gubrium \& Holstein, 1997) then took a technical turn within the discipline. While attempts to control the free-for-all conduct of qualitative research had a number of positive effects, such as the development of some shared values and criteria in the mainstream community (e.g., Klein \& Myers, 1999; Walsham \& Sahay, 1999), and an increase in sophistication of methodological discourse, the unintended (and mostly undesirable) consequence was the creation of a bewildering set of guidelines and criteria faced by an author, any of which could be potentially applied to his/her manuscript by a referee. The methodological criteria popularized by sources such as Yin (1994), Strauss and Corbin (1998), Klein and Myers (1999), Lee (1989), Dubé and Paré (2003), Walsham (1995a), and Golden-Biddle and Locke (1993) - to mention a few-were demanded by reviewers and editors. While we do not believe that an individual reviewer would demand the adherence to all of these criteria, when one considers the criteria-in-use in evaluations by two or three reviewers, an associate editor, and a senior editor (as is the structure of a review team in many journals), all of whom might privilege different methodological priorities and preferences, it is not difficult to see that qualitative authors were (or are) being placed in a fairly impossible situation in terms of meeting methodological expectations. In this stage, methodological criteria and references are utilized by authors or imposed by evaluators without much heed to whether the criteria are relevant to a particular genre, thereby leading to a lack of internal consistency between the various elements of the qualitative study.

\footnotetext{
${ }^{6}$ As the first-generation matures, we see the entry (i.e., initiation) of the "second-generation" approaches, such as discourse analysis, virtual ethnography, and, most recently, computational approaches for studying digital trace data, and
}

Finally, we are beginning to see some evidence of the emergence of the maturation stage, though this is not very widespread and is limited to some research subcommunities. We see that the first-generation qualitative genres are being firmly established in these subcommunities, and there is a recognition that each genre (or established subgenre) carries a certain set of underlying philosophical and methodological assumptions, and consequently, specific guidelines, criteria, and references, which, when acknowledged by authors, provide an internal consistency to the study. Publication of, and widespread acknowledgement of exemplars for each genre, as well as the development of a critical mass of specialists capable of evaluating each genre ${ }^{6}$ are needed to support the gradual transition to and maintenance of such maturation within the entire discipline.

Interestingly, parallel with the recognition that different genres exist, and that they need to be executed and evaluated differently, there is also an emerging trend in some subcommunities toward calling for adopting a "pragmatic approach" to methodology by mixing and matching quantitative and qualitative approaches (Venkatesh, Brown, \& Sullivan, 2016; Walsh et al., 2015), inductive and deductive reasoning, small data and big data (Abbasi, Sarker, \& Chiang, 2016), and in general, promoting a less stringent view of the different genres such as the grounded theory methodology (Birks, Fernandez, Levina, \& Nasirin, 2013). This, we believe, might help loosen the stranglehold of the patterns associated with the control stage, but can, unless practiced with caution and reflexivity, lead to the arbitrariness of methodological application associated with the contagion stage. It is unmistakable, however, that despite signs of maturation in certain subcommunities, the leading mainstream journals in the discipline, for the most part, continue to enact patterns associated with the control stage. Consequently, we focus much of our attention in the paper on such patterns.

\section{A More Detailed Look at the "Control Stage"}

One of the unanticipated and arguably undesirable consequences of the focus on "method talk" and the emphasis on "criteria-ology" for good qualitative research has been the often impossible-to-meet (and sometimes inappropriate) methodological demands placed on the authors of qualitative work. Typically these problems arise because: (a) authors may have crafted their work with criteria that may not be well

we expect that their evolution will have similar (if not the same) patterns as those experienced by the first-generation approaches. 
suited for the nature of their work; (b) evaluators may expect that the work satisfy their favorite criteria (which could be made explicit in the review process or remain implicit) irrespective of the nature of the work being assessed; and/or (c) there is a mismatch between the methodological principles applied by the authors and the methodological criteria used for assessment by evaluators. For many readers, this might seem an aberration rather than an enduring pattern. However, the authors of this editorial believe, based on firsthand observations, that this is a common occurrence, and many manuscripts suffer the consequences (usually rejection) of misreview, with evaluators imposing a set of expectations based on criteria that are alien to the creators of the work. We would like to reiterate that while an individual review team-member may not expect that a wide range of possible criteria be satisfied, the scenario for authors that can (and actually does) arise, is that different members of the review team have preference for different criteria (as mentioned earlier), forcing the authors to satisfy an unreasonable superset of criteria, unless there is strong editorial intervention. A key point worth mentioning here is that such a situation arises not necessarily due to a clash between qualitative-quantitative subcommunities, but due to a clash between different traditions of qualitative research. Markus (1997) alerted us 20 years ago to precisely this point, noting, "When we [qualitative researchers] review the research of [our] qualitative research colleagues, we 'diss' [i.e., disrespect] those who do not do qualitative research exactly as we do ... this is pure and simple prejudice" (p. 14 , emphasis added).

To illustrate this pattern of behavior, we offer two simple examples adapted from review packages of leading IS journals which illustrate how review comments can be at odds with the type of qualitative research being conducted (Table 1). The first example is from a positivist case study, while the second example is from an interpretive case study. In the first instance, the associate editor for the manuscript expressed concern about the lack of richness and deep insights, echoing the referees' concerns that the work was fact-oriented and distant. In the second instance, the review team seemed unconvinced by the results because of: (a) the "bias"; (b) the lack of evidence on how results were "extracted" from the data; and (c) results not being validated by the subjects' agreement. See Table 1 for a summary of concerns.

Table 1. An Example Illustrating a Mismatch between Authors' and Evaluators' Methodological Stances

\begin{tabular}{|l|c|}
\hline & \multicolumn{1}{c|}{ Review comments } \\
\hline Positivist case study manuscript & $\begin{array}{c}\text { AE: The authors' use of the case study approach is found to be lacking in richness and } \\
\text { deep insights that one normally expects of high quality case studies. [R\#j] finds the } \\
\text { narrative very . . "fact-oriented,” while [R\#k] describes it as "distant.” }\end{array}$ \\
\hline Interpretive case study manuscript & $\begin{array}{r}\text { Reviewers raised concerns regarding the following: } \\
\text { The authors' interpretation is biased. } \\
\text { It was not clear how the authors' inferences and conclusions were extracted from } \\
\text { the data (i.e., there was a lack of transparency). } \\
\text { The authors did not offer evidence to demonstrate that the conclusions of the } \\
\text { work resonated with the participants. }\end{array}$ \\
\hline
\end{tabular}

As many readers will appreciate, one underlying cause for the perceived deficiencies in the two manuscripts is that review team members in both cases were using their own notions of how to judge a qualitative study. When one considers that the first is a positivist case study, what may have seemed like fatal flaws (e.g., lack of "richness" and "deep insights"; "fact-oriented" and "distant") to a reviewer actually should be viewed as methodological strengths of that genre of work, consistent with the values associated with positivism (as per the understanding of the term within the discipline). Similarly, when one considers the fact that the second is an interpretive case study, the notion of "bias" could become less relevant or appear misplaced. Further, the idea of "extraction," which reflects a strict grounded or inductive view, overlooks the possibility that "interpretation is often productive, not reproductive" and imaginative (Alvesson \& Sköldberg, 2009). In fact, even Hirsch (1967), who is associated with an objectivist form of hermeneutics, notes that there are no mechanistic rules for formulating an interpretation, making the idea of systematic extraction of findings from data, nothing more than a mirage in many interpretive studies. Finally, given that knowledge is considered contextual within many epistemological traditions (especially for those adopting an interpretive perspective), scholarly interpretations weaving together second-order constructs are not necessarily recognizable in the world of subjects where first order concepts are used (Lee, 1991; Walsham, 1995b), and, thus, direct validation by "member- 
checking” (Trauth \& Jessup, 2000) is not necessarily meaningful in every study.

Although the examples we provide are basicdeliberately so-and self-evident for many readers, they highlight the point we wish to make even more emphatically. They show that many evaluators apply implicit evaluation criteria that are incompatible with the authors' methodological assumptions and principles used, even though the labels of "positivist case study" and "interpretive case study" are fairly well known and signal what kinds of methodological expectations are reasonable. In other words, what is lacking is a common understanding, between authors and evaluators, regarding appropriate criteria to judge the work. It is not very difficult to imagine how much this problem would be compounded if the authors of the two manuscripts discussed in the above examples were not cognizant of the nature of their own work and characterized the two studies using the generic label of "case study" along with a set of citations that cut across the various traditions of case research.

The key point we make in this section is that both authors and evaluators need to align, based on the chosen qualitative genre, their expectations about the methodology for a work to be evaluated fairly, and without "prejudice." At the least, this implies that authors should signal the nature of their work by appropriately labeling their methodological approach, which we refer to as "genre," and invoking appropriate methodological guidelines and references. The term "genre" recognizes the fact that each approach is associated with a set of assumptions, a style of inquiry and representation, a certain set of methodological guidelines and methodologists, and, consequently, expectations of what constitutes internal consistency, from a methodological standpoint. ${ }^{7}$ In the next section, we identify some of the elements that help define the different genres, following which we describe the more prevalent types of qualitative research in the IS literature.

\section{Four Elements Underlying Qualitative Research Genres}

The term "genre" has been defined in many ways, such as "a category of artistic, musical, or literary compositions characterized by a particular style, form, or content." ${ }^{8}$ A more specific way in which genre has been described is as "composed of a constellation of recognizable forms bound together by an internal dynamic" (Campbell \& Jamieson, 1978, p. 21). In this editorial, we use the term to differentiate among the various types of qualitative research having diverse conventions for conducting, representing, and justifying the studies. Not only are assumptions underlying each methodology distinct, but the argumentation and rhetorical style are also distinct (e.g., Harvey, 1997). Understanding the characteristics of a given genre and/or where the genres may overlap is important to conducting quality research. The genre determines how a study is designed, how the quality of the research is ensured, and on what basis the work should be judged with respect to its methodology. As evidenced above, when authors and reviewers are out of sync with regard to genre, meritorious manuscripts may be criticized and rejected. More rarely, manuscripts lacking in methodological awareness and consistency may be published, potentially leading to embarrassment for the authors or the published paper (due to obvious errors and inconsistencies) or to these errors and inconsistencies then being emulated by novice scholars.

A manuscript can be seen as a device for communication between the author and the audience, and inherent in the manuscript is the genre which the author chooses to communicate with the audience. What elements influence the genre of the manuscript? Clearly, a host of elements can potentially contribute to the nature of a qualitative manuscript. Below, we offer four key elements that we see as relevant to the effective communication between the researcher and the audience (which includes editors, reviewers, and readers of the paper): (a) the researcher's conception and use of data, (b) the nature and role of theory in the study, (c) the data analysis strategy used in the study, and (d) the nature of claims regarding the findings of the study (Fig. 1).

Nevertheless, methodology continues to hold a prominent place in scholarly discourse, and our paper focuses on this aspect.

8 Merriam-Webster Dictionary. Retrieved from https://www.merriam-webster.com/dictionary/genre.
${ }^{7}$ We acknowledge that methodological concerns are but one aspect of qualitative research, some others being the level of theoretical engagement and nature of contributions (Sarker et al., 2013). Further, the value of findings sometimes is not particularly related to the methodological quality of a study. 


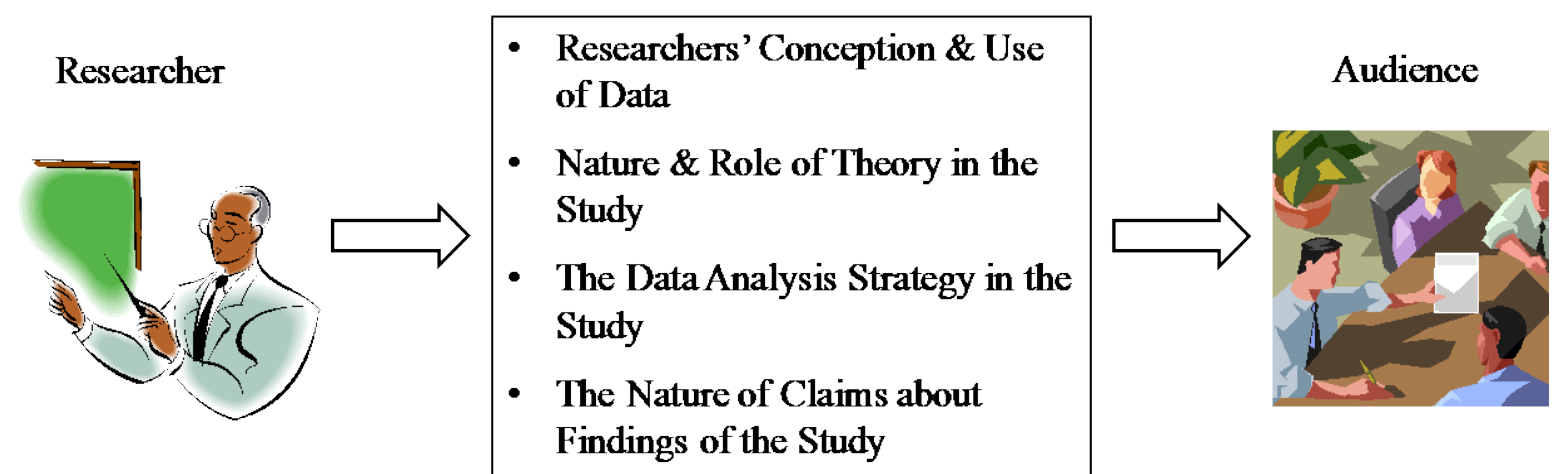

Figure 1. Four Elementa of Qualitative Genres

\subsection{The Researcher's Conception and Use of Data}

There is a variety of empirical material (i.e., data) used by qualitative researchers. These include: texts, text analogues (behaviors), images, and even sounds. Qualitative data may be obtained through interviews, observations, historical artifacts such as documents, and so on. Sources of data can be categorized as being researcher-provoked data, that is, data which exists because of a researcher's intervention in the form of an interview, focus group, etc.; user- generated content, that is, data available through digital content, such as social media or blog posts (Vaast, Davidson, \& Mattson, 2013); or naturally occurring talk such as that formed in everyday conversation (Silverman, 2001, p. 159). Naturally occurring talk can include written text, as well as technically enabled conversations via email or online forums (e.g., Kozinets, 2002; Vaast \& Walsham, 2013). The variety of data can be appreciated by, for instance, considering the different types of interview data (Schultze \& Avital, 2011). Interviews can be of a rational type, with the assumption that a skilled interviewer can find the objective truth, or interviews can be of the creative type, where the goal is for the researcher to go beyond the interviewee's "rational façade" and understand the interviewee's feelings and thoughts (Fontana \& Frey, 2000, p. 663). Researchers might even use an active interview style where the interviewer coconstructs reality jointly with the interviewee (Fontana \& Frey, 2000; Holstein \& Gubrium, 1995).

In any study, there are assumptions-in-use about the nature of data, that is, how the data is conceptualized and used in research; these assumptions toward the data influence the choice of (or appropriateness of) the genre for a study. Below, we illustrate some of the different types of data qualitative researchers may use:
- Facts: Represents objective, and publicly verifiable observations and truths (Silverman, 2001), such as "XYZ Corp's IT budget was \$ 6,000,000 for 2014."

- Subjective understanding: Seeks to represent an "authentic account of subjective experience," rather than some objective truth (Silverman, 2001, p. 90). An example might be an individual discussing her simultaneous sense of freedom and bondage as a result of mobile device use.

- Socially constructed reality: Seeks to represent reality that is created through a social process, and apprehended by an individual or shared in a group (Astley, 1985; Berger \& Luckmann, 1966). An example might include how a community of practice develops a shared understanding of being a "slave" to a process diagramming tool, or the tool as seen as a "manipulator" of human relationships.

- Negotiated meanings by subjects and researchers: Seeks to represent meaning created through an interaction, that is, a naturally occurring social encounter between the interviewer and interviewee (Fontana \& Frey, 2000; Silverman, 2001). An example might be an interviewer asking an interviewee to imagine situations specified by the interviewer, and then the interviewer and the interviewee jointly exploring different possibilities or meanings.

- Persistent text that is separated from the context: Seeks to represent meaning as ascribed by the receiver to texts irrespective of what the originator's intention or meaning was. Given the separation in time and space between text originators and text recipients, it is sometimes not possible to seek validation or clarification 
from the originator and it is sometimes appropriate not to seek validation or clarification from the originator. For the former, the originator's intended meaning could still very well be the appropriate meaning or "data" for the researcher to interpret or "collect." For the latter, the originator's intended meaning, whatever it might be, is one thing, but the researcher could also take the position of knowing the author better than the author knows himself, which could result in a very different understanding of the data or text. (Boland, 1991; Ricoeur, 1991)

\subsection{The Nature and Role of Theory in the Study}

Engagement with theory is considered to be a crucial element of qualitative research, given that theory endows data "with order, sense, and meaning" (Harrington, 2005, p. 5); yet, the nature and purpose of theory will vary depending on the research approach. For example, theory may be introduced upfront to guide the design of the study, theory may be adopted in the methodology section to support the data collection and analysis process, or theory may be developed at the end as the final product of the study (Eisenhardt, 1989; Walsham, 1995a). The authors' conception and use of theory is largely dependent upon the chosen genre of the qualitative research. Many perspectives on theory (and theorizing) are discussed in the literature (e.g., Gregor, 2006; Henfridsson, 2014; Leidner, 2018; Sutton \& Staw, 1995; Weber, 2012). Conceptions of theory include:

- $\quad$ a set of generalizable, falsifiable propositions or laws (Doty \& Glick, 1994);

- $\quad$ a coherent framework with identified variables and relationships (Gregor, 2006);

- a "conception or mental scheme" (Gregor, 2006), a "lens" or a "scaffolding” to support the iterative process between data collection and data analysis (Eisenhardt, 1989; Van Maanen, Sørensen, \& Mitchell, 2007; Walsham, 1995a);

- a narrative, or "an account of a social process” (DiMaggio, 1995; Molnar, Nandhakumar, \& Stacey, 2017);

- as fundamentally not true, and not objective (Mintzberg, 2005) but as fiction, that is the product of “disciplined imagination” (e.g., Weick, 1995);

- an "enlightenment," or artful and exciting insights” (DiMaggio, 1995, p. 391).

Indeed, Van Maanen et al. (2007, p. 1146) have noted that "theory can generate and shape method," and vice versa. Thus, it is reasonable to expect, given the intricate relationship between theory and methodology, that a study seeking to enlighten through artful and exciting insights would be methodologically distinct from a study that is engaged in developing or testing well-defined falsifiable propositions linking independent and dependent variables. In other words, the various assumptions associated with different qualitative research genres have important implications for both theory and method (Van Maanen et al., 2007). For example, authors working within certain interpretive traditions like "interpretive case studies” (Walsham, 1995a) are likely to use theory as a lens to interpret or unfold complicated social processes, whereas authors adopting a positivist stance, as in "explanatory case studies" (Yin, 1994), would be more inclined to view theory as generalizable, falsifiable propositions, or "frameworks" to generate propositions that can be validated or invalidated using empirical data.

\subsection{The Analysis Strategy Used in the Study}

Analysis refers to procedures that are applied to the data to derive results or findings; yet, just as in the case of "data" and "theory," there is a lack of clarity on what the term "analysis" means. A review of the literature reveals many different labels and strategies for analyzing data. It is clear that different genres would have affinity for different approaches and techniques for engaging with empirical material (Denzin \& Lincoln, 2000). The nature of analysis in a qualitative study plays an important role in defining the appropriate conventions for writing, justifying, and evaluating the study. Here, we describe four analysis strategies that are frequently utilized in qualitative research in IS:

- "Polyphonic" presentation, where authors allow subjects with multiple perspectives to "speak for themselves" (Travers, 2001). Authors using such a strategy merely present interview text in which the authors are an “impersonal narrator" providing a platform for expression by the multiple voices of subjects, rather than imposing their own understanding of the text (Travers, 2001).

- Induction / Abduction, which emerges from the data without authors imposing preexisting expectations, and moves toward generating concepts and theories from the data (Patton, 1990). Authors adopting the inductive approach often follow the "ladder of analytic abstraction" (Miles \& Huberman, 1994), or coding strategies (Saldaña, 2012), including but not limited to open coding, axial coding, and selective coding recommended by some grounded theory methodologists (Strauss \& Corbin, 1998). Many scholars maintain that induction goes hand in hand with abduction (Hammersley, 2008; Van de Ven, 2007), a research logic that represents 
“a creative form” (Van de Ven, 2007, p. 140) and "acknowledges the fact that conceptualizations do not result from a mechanical coding process but involve 'an intellectual act, a mental leap' that is at the very heart of a 'cognitive logic of discovery", (Reichertz, 2007, p. 220, qtd. in Sarker, Chakraborty, Tansuhaj, Mulder, \& Dogerlioglu-Demir, 2013, p. 9). Abduction explicitly recognizes the added element of human creativity needed to reason from data to theory, for which induction alone may be insufficient (Holeman \& Barrett, 2017).

- Deduction: Unlike induction, "which involves the drawing of conclusions that exceed the information contained in the premises" making it a suitable approach for supporting discovery, deduction does not "go beyond the content of the premises" (Van de Ven, 2007, p. 124), and guides the (in)validation of proposed relationships using hypothetico-deductive logic (Lee, 1991). Such an analysis strategy can be operationalized through pattern matching, which compares empirically generated evidence with predicted patterns (Dibbern, Winkler, \& Heinzl, 2008; Yin, 1994).

- Interpretation, which appears in at least two varieties: (a) Elaboration, or constructing a theory-informed narrative using a (meta)theoretical lens or a theoretical scaffolding (Bernardi, 2017; Su, 2015; Walsham, 1995a), and (b) iterative understanding with a "guess" followed by "validation"-i.e., the humanistic moment followed by the scientific moment of the hermeneutic circle, until all apparent anomalies in the data cease to exist (Alvesson \& Sköldberg, 2009; Hirsch, 1967; Ricoeur, 1991).

Given that the four analysis strategies are quite different, it follows that each analysis strategy would have a greater (or less) fit with a given qualitative research genre.

\subsection{The Nature of Claims about the Findings of the Study}

Qualitative studies have a variety of aims and make different types of contribution claims. The process of presenting the findings is a rhetorical process relying on the elements of persuasion such as those deriving from the Aristotelian elements of logos (clarity of logic and empirical evidence), pathos (ability to stir the imagination of the reader and garner empathy), and ethos (the authenticity and legitimacy that the author develops through the argument) (Van de Ven, 2007). Despite these roots in rhetoric, each genre may emphasize these rhetorical devices in varying degrees. For example, a realist account may emphasize logos and ethos, but an imaginative account may emphasize pathos and ethos. Qualitative research can produce various types of contributions, with claims ranging from mere description to full-blown theory creation (Creswell, 1998). Along similar lines, Barrett and Walsham (2004) discuss several types of contributions manuscripts may seek to make and claim, and Flyvbjerg (2006) notes how case studies make very different contributions based on their "broader philosophical positions” (p. 238). Specifically, a study may seek to make one or more of the following claims:

- uncover what really happened ("the search for truth”) (Hirsch, 1967), i.e., represent reality accurately (e.g., Van Maanen, 1988);

- develop a plausible understanding of a poorly understood phenomenon (e.g., Walsham \& Sahay, 1999);

- generate new concepts and novel insights (Walsham, 1995a), and move from description to abstraction (Klein \& Myers, 1999; Eisenhardt, 1989);

- formulate universally applicable causal explanations (Miles \& Huberman, 1994; Yin,1994);

- construct evocative, experiential text to "capture, even reenact, the subject's experience and to describe that in full emotional color" (Gubrium \& Holstein, 1997, p. 9); or even

- seek to influence the views of a specific audience, reflecting a "moral commitment" to a cause or interest group (Schweizer, 1998).

Again, we believe that qualitative studies are likely to achieve internal consistency when the nature of contribution claims matches the qualitative research genre.

\section{Linking the Elements to Genres and Criteria}

The four elements of qualitative research discussed above (briefly: data, theory, analysis, and claims), when combined in various ways, speak to the underlying issue of "fit" with different qualitative research genres. As Campbell and Jamieson (1978)'s definition of genre suggests, "a genre is given its character by a fusion [of the different elements], not by its individual elements" (p. 21). Given that the number of combinations conceivable with different conceptions of data, theory, analysis, and contribution claims can be expected to be unmanageably large, we do not see it as feasible or helpful to construct a decision table that provides guidance on a suitable genre indicated by each combination. Instead, we present a map of the prominent first-generation genres and illustrate how the four elements can be used to differentiate the genres (or subgenres) thereby 
providing insight into what constitutes internal consistency within each genre.

Specifically, in Figure 2a, consistent with Walsh et al. (2015), we map prominent first-generation qualitative research genres visible in the IS literature across two dimensions: (1) data-centric $\leftrightarrow \rightarrow$ interpretationcentric, and (2) inductive $\leftarrow \rightarrow$ deductive. The first dimension is roughly equivalent to whether the approach to data is objective or subjective. In light of critical commentaries highlighting the problematic nature of subjective-objective dualism (Deetz, 1996), we use the terms "data-centric" and "interpretationcentric" to characterize the nature of the qualitative study. A data-centric approach (at the extreme) takes data as an entity representing a fixed meaning, and emphasizes the use of systematic logical operations of the data to derive knowledge or findings. In contrast, an interpretation-centric approach (at the extreme) sees data as flexible "texts," without an inherent meaning or with meaning that is not tied to the originator's intentions, which enables imagination of possibilities for researcher(s). Creative mental leaps, emotions, and/or ideologies are not only intertwined but regarded as valuable in the collection and analysis of such texts. The second dimension is useful in differentiating between genres depending on whether they are primarily engaged in discovery (induction) or confirmation (deduction). In induction, the process of reasoning moves from the particular (data from the local setting) to the general (abstractions, or the theory) (Hammersley, 2008), while in deduction, "the conclusion ... follows as a matter of logical necessity from the major premise (the theory) as applied to the minor premise (the data or facts of the local setting)” (Lee \& Sarker, 2008).

\subsection{Selected Qualitative Research Genres in IS Literature}

Turning our attention to Figure 2a (below), we present five genres that we see as the prominent firstgeneration qualitative approaches adopted in the IS community. We note that our goal is not to provide a comprehensive coverage of all qualitative approaches, but to be illustrative of the nuances within these prominent genres. ${ }^{9}$ We would like to emphasize that while the map does highlight key differences in the

${ }^{9}$ For example, while the genres discussed are undoubtedly relevant to action research studies, a full characterization and genres in terms of the two chosen dimensions, there are many differences that are not obvious, primarily because of the overlap among methodologies. Below we will briefly discuss each of the genres based on how they utilize the four elements of a qualitative study, and also point to a small subset of possible variations within each genre.

Positivist Case Study: As shown in Figure 2a (see below), the genre of positivist case study predominantly occupies the upper-right quadrant of our map. Guided by the philosophical assumptions of positivism (as understood within the mainstream IS discipline), researchers of this genre tend to treat qualitative data as representative facts or shared reality, and theory as generalizable, falsifiable propositions. Analysis within a positivist case study is often focused toward deductive validation of theory using hypothetico-deductive logic (Lee, 1989) and pattern matching (Yin, 1994). However, positivist case research can also include inductive theory building (Dubé \& Paré, 2003; Eisenhardt, 1989). Studies of this genre generally claim validation or falsification of a theory (the deductive variants), or development of constructs and articulating relationships among them (the inductive variants).

Grounded Theory Methodology (GTM): Researchers adopting the genre of grounded theory methodology (GTM) tend to hold a more data-centric view-i.e., they generally treat data as holding representative facts or shared reality. Data analysis involved in GTM is predominantly inductive in nature, involving systematic theoretical sampling and systematic coding (e.g., open coding, selective coding, theoretical coding [Glaser \& Strauss, 1967]) to develop conceptually dense theory. A priori theory may be used as a sensitizing element, but it should not drive or constrain theory building (Birks et al., 2013). A key tenet in GTM is that the theory emerges from (rather than being forced onto or tortured out of) the data, with analysis taking the form of an iterative process consisting of constant comparison between the data and its relationship to the emergent theory (Birks et al. 2013; Urquhart et al., 2010). Theoretical claims can be typologies, theories of explanation, or even generalizable, falsifiable theories of explanation and prediction (Gregor, 2006) depending on the precise position of the given study on the map.

meaningful mapping of action research studies would require additional dimensions, beyond the two used. 


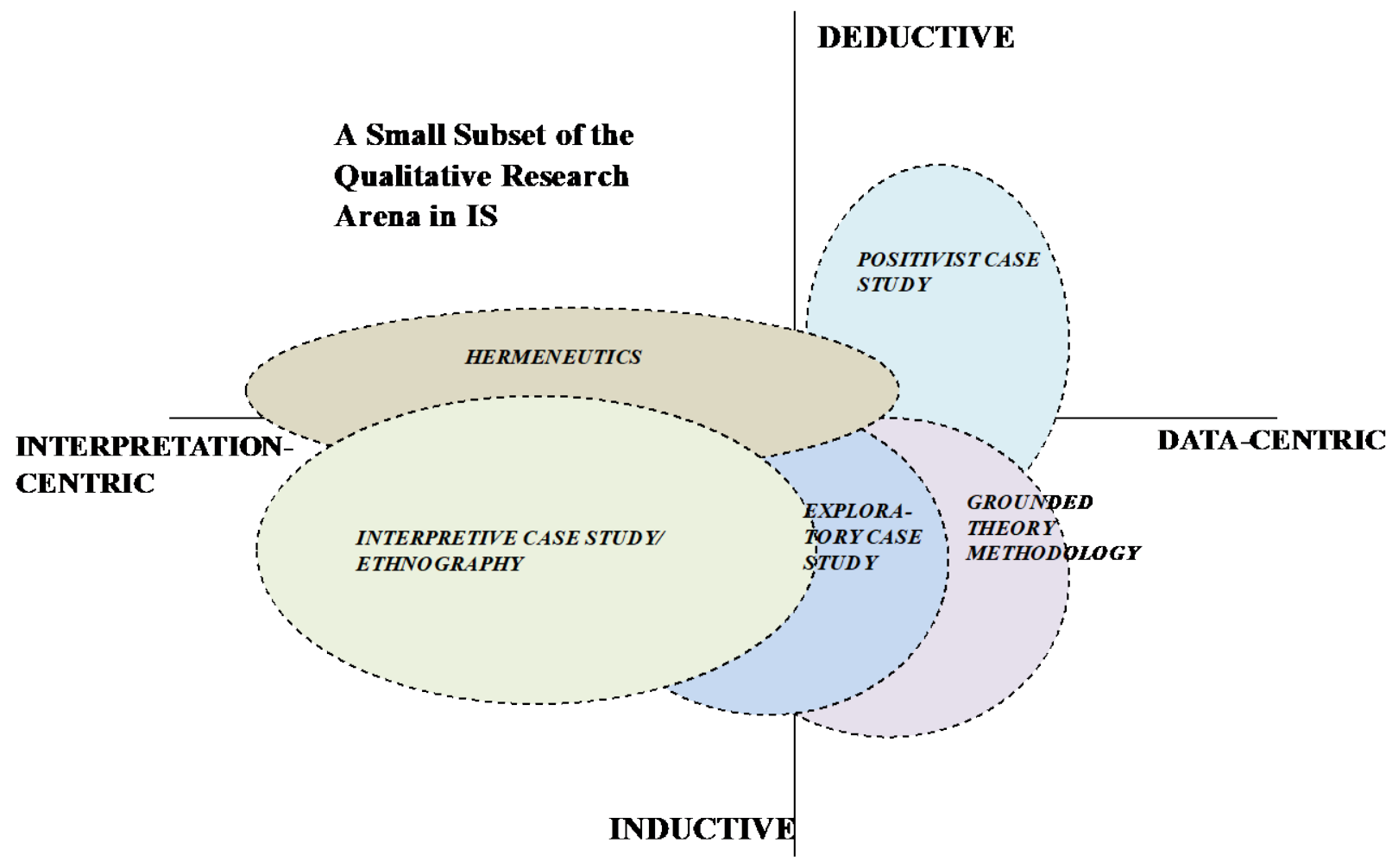

Figure 2a. A Map of First-Generation Genres in Qualitative Research

Exploratory Case Study: The genre of the exploratory case study is a popular yet confusing one, with substantial variations in philosophical assumptions across studies, such as soft positivism, critical realism, naive realism, or sometimes no coherent set of assumptions. Beyond the promise to explore, the broad label often does not signal much to the reader, especially about the nature of the case study. This genre tends to involve inductive reasoning, and in most cases, studies are positioned as data-centric, where data is generally treated as representative facts that lead to a realist recounting/reconstruction of events (Yin, 1994). Typically, some theory is used up-front to guide the design and execution of an exploratory case study, if only to set a general "course" or direction (Yin, 1994). When theoretical contribution is offered, it might be in the form of propositions or frameworks (Yin, 1994). Analysis within exploratory case studies often involve "polyphonic" presentation (Travers, 2001) or induction by engaging in some commonsense way of developing an accurate picture of the situation and implications, which generates claims in the form of a new framework, propositions, or lessons

${ }^{10}$ In our view, sometimes qualitative researchers use the label "exploratory" unnecessarily, when their research is actually quite definitive. Usage of the "exploratory" label in these instances could very well be considered defensive. learned. In addition, the conclusions of many exploratory case studies tend to be positioned as provisional, and they generally serve as a "prelude" to additional research (Yin, 1993, p.5). ${ }^{10}$

Ethnography / Interpretive Case Study: ${ }^{11}$ Ethnography is a well-established qualitative research genre with a long history rooted in sociology and anthropology (e.g., Agar, 1986; Atkinson \& Hammersley, 1994; Van Maanen, 1988), with mature subgenres, such as realist ethnography, confessionalist ethnography, impressionist ethnography (Van Maanen, 1988), and critical ethnography (Thomas, 1993). More recently, ethnographic research has been extended to the virtual domain, and referred to as virtual ethnography (e.g., Hine, 2000). Within the discipline of IS, the ethnographic tradition (Harvey \& Myers, 1995) has largely been subsumed within the genre of interpretive case study (Walsham, 1995a). As shown in Figure 2a, ethnography / interpretive case study occupies a wide range of area, where different points could vary with respect to data, theory, analysis, and claims within the genre. While the studies may all be characterized as

\footnotetext{
${ }^{11}$ It should be noted that even though the two genres are different, the representation of them on the two-dimensional map for the IS discipline overlaps.
} 
“interpretive,” the range of data and analysis can vary from attempting to be an accurate representation of reality on the right side of the map, perhaps derived through careful coding and triangulation, to a more impressionist strand toward the left side of the map, with experiential, imaginative, and evocative reading of texts, potentially even involving interpretively flexible poetry and sketches. "Breakdowns" and "mysteries" between empirical data and existing theory can lead to novel and improved theory (Alvesson \& Kärreman, 2007). Analysis is largely inductive in nature, though abduction, that is, a mental leap from data to concepts/insights (Reichertz, 2007) plays a larger role as we move left on the map (Figure 2a). Theory, viewed as a lens or scaffolding, may be used both as an up-front guide to inform the research project and as an outcome of the study (Walsham, 1995a). The resulting theory may involve a framework or midrange theory, be more imaginative, or have the pragmatic goal of influencing the views of the audience. Claims take the form of novel insights and may be presented as theory, a framework, or (moving left on the map) a plausible reinterpretation of the phenomenon. There is also the constant tension within this genre between revealing local and larger truths (e.g., Prasad, 1997).

Hermeneutics: The term hermeneutics has two broad meanings; in a "weak" sense, hermeneutics may be used synonymously with any form of interpretive research approach while, in a "strong" sense, it refers to the interpretation of texts and text analogues (e.g., social behaviors and artifacts) relying on: (a) epistemological insights from various strands of hermeneutic theory (Boland, 1991; Prasad, 2002), and (b) the hermeneutic circle, an iterative approach that allows the reader to comprehend parts of the text in terms of the whole and the text as a whole in terms of its various parts (Klein \& Myers, 1999; Lee, 1991). The genre of hermeneutics generally refers to studies that adopt a "strong" sense of the term. As evident from the large area covered by Figure 2a, many subgenres of hermeneutics exist (e.g., Gadamer, 1989, 2001; Grondin, 1997; Hirsch, 1967; Myers 1995, 2016; Phillips \& Brown, 1993; Ricoeur, 1991; Smith, 1993). For hermeneutics researchers, the nature of data can vary from distantiated texts and "text analogues" (Boland, 1991; Ricoeur, 1991) to objective, textualized utterances linked to the originator's intentions. Theory may be conceived as a "guess" or disciplined "imagination" with studies. In general, analysis involves iterative reading of the text until no apparent absurdities exist (Agar, 1986; Sarker \& Lee, 2006). Moving from left (the more interpretation-centric region) to right (the more data-centric region) on the map, the resulting understanding (i.e., claims) may vary from (a) a plausible, creative, and internally coherent understanding of the texts, to (b), the reconstructed accurate understanding of reality and truth (Hirsch, 1967).

We summarize our discussions in Figure 2b, which presents the genres and their utilization of the four elements. We use the alphabets a-g to highlight the fact that there are variations within certain genres, and in our discussions, we are characterizing a point on the map within a specific genre, rather than the genre as a whole. This is because, within a broad genre, there could be variations with respect to the four elements (i.e., data, theory, analysis, and claims) discussed above. 


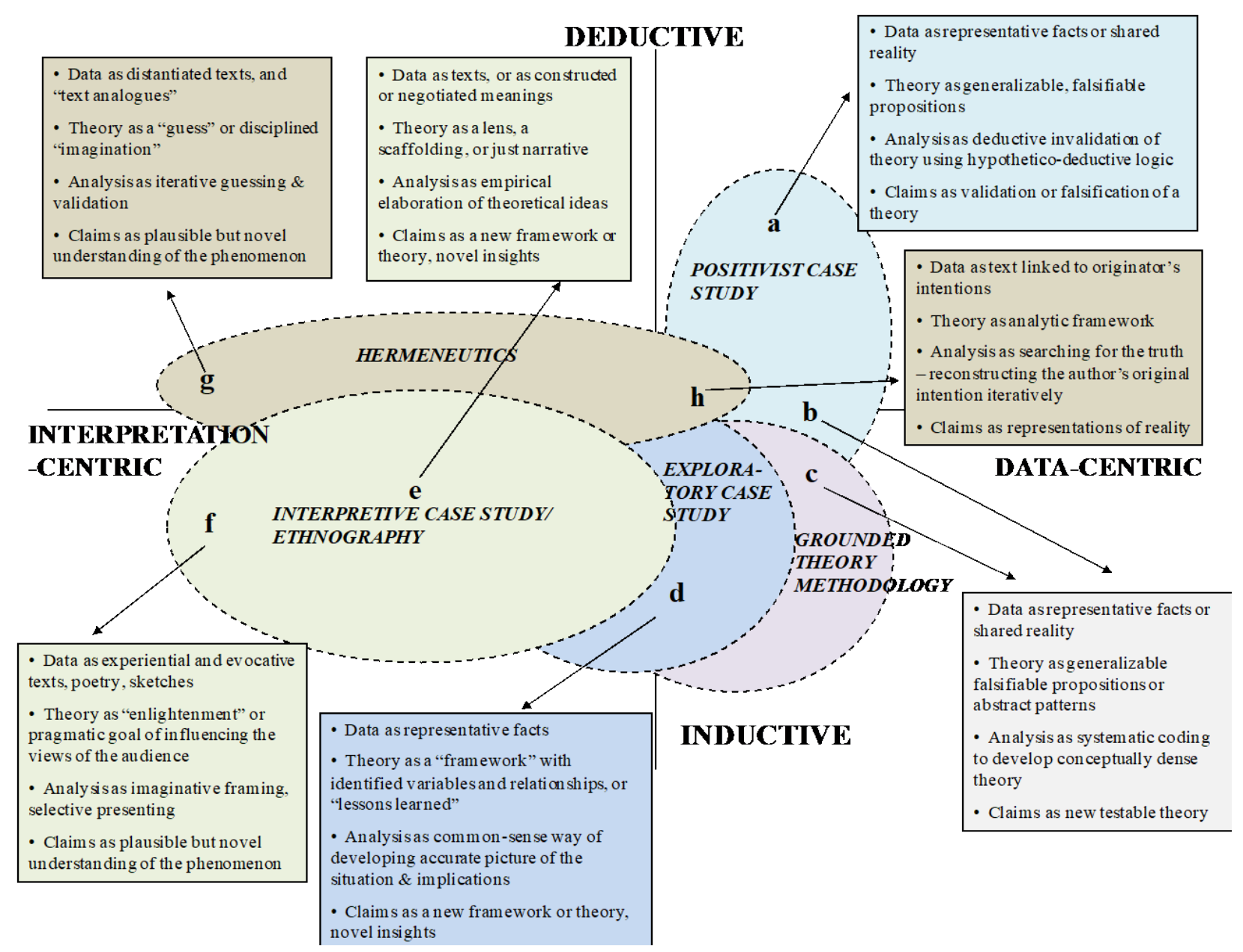

Figure 2b. First-Generation Genres with Possible Nature of Data, Theory, Analysis, and Claims

\subsection{Genres and Evaluation Criteria}

Having highlighted the characteristics associated with first-generation qualitative research approaches, we now turn our attention to potential evaluation criteria. We argue that because of the differences among the genres (regarding how each genre approaches data, theory, analysis, and claims), it is reasonable to expect that each would need to be conducted and evaluated differently, using an appropriate set of guidelines and evaluation criteria. Furthermore, as highlighted in the discussion above, and evident in the figures, variations exist within the same genre. For instance, interpretive case studies can vary from those holding a realist view to those holding an impressionist view. Consequently, it would be inappropriate to impose an identical set of criteria on these two subgenres of interpretive case study. Similarly, positivist case studies engaged in deductive theory testing should be treated differently from those engaged in inductive theory building. Therefore, we argue that the evaluation criteria should not only match the genre itself, but also the relative location of where the study is positioned on the map. Figure 2c presents such a view. Table 2 summarizes selected relevant evaluation criteria for each genre and each location on the map, and also presents selected methodological and criteria references for each set of criteria. Again, we note that our goal here is not to provide a complete listing of criteria for each genre (developing criteria for each genre would require a separate editorial!), but to illustratively highlight the fact that relevant criteria for good qualitative research vary drastically based on the genre of the study, and indeed, within genres, based on the study's location on the conceptual map.

In summary, we have presented the four elements underlying qualitative research genres-namely, data, theory, analysis, and claims. Next, we mapped out the 
prominent first-generation qualitative research genres within IS using two dimensions and discussed the characteristics of each genre in terms of the nature of these four elements. However, as our discussion has highlighted, just as a qualitative study itself is not a “monolith” (Gubrium \& Holstein, 1997), each genre also consists of subgenres and variations, despite there being shared characteristics within each genre. Therefore, when evaluating a qualitative study, the criteria used should depend not only on the genre adopted, but additionally, on the implied or stated position of the research study on the map. In other words, our goal here is not so much to associate a comprehensive set of characteristics, criteria, and references with each genre, but to highlight the fact that these attributes vary across, and even within genres-more specifically, they vary across different points on the map. Because of the overlaps among genres, say, GTM and case studies (Seidel and Urquhart 2013), some genres also share criteria.

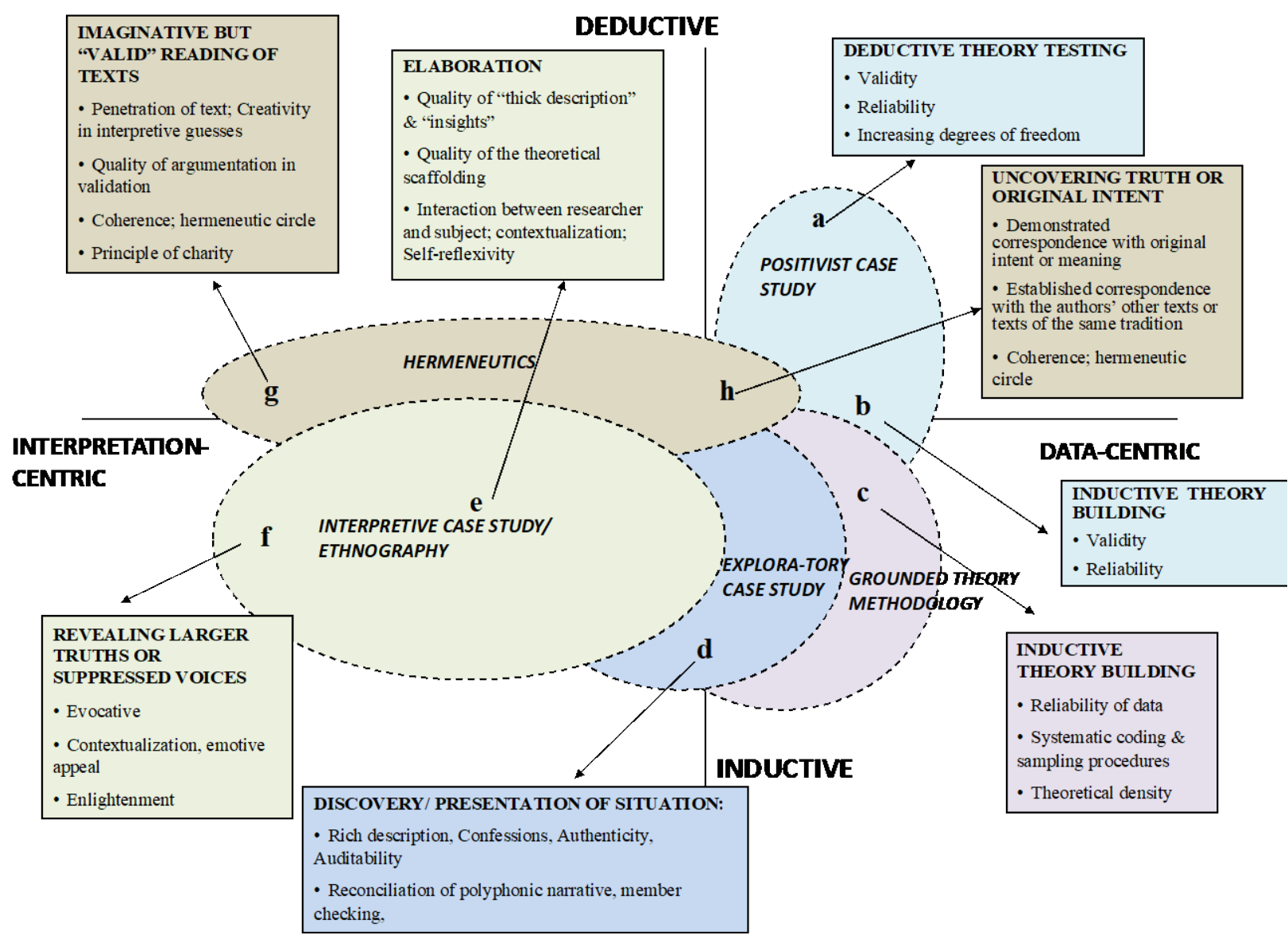

Figure 2c. Genres and Sample Evaluation Criteria for Different Points of the Map 
Table 2. Selected Genres / Subgenres with Possible Evaluation Criteria \& References

\begin{tabular}{|c|c|c|}
\hline $\begin{array}{c}\text { Location on the map / Genre or } \\
\text { Subgenre }\end{array}$ & Sample evaluation criteria & $\begin{array}{l}\text { Sample methodological and criteria } \\
\text { sources frequently used in IS }\end{array}$ \\
\hline “a” Positivist case study (deductive) & \begin{tabular}{|cl} 
Deductive theory testing \\
- & Validity \\
- & Reliability \\
- & Increasing degrees of freedom
\end{tabular} & $\begin{array}{l}\text { Dubé and Paré (2003) } \\
\text { Lee (1989) } \\
\text { Yin (1994) }\end{array}$ \\
\hline "b” Positivist case study (inductive) & \begin{tabular}{|cc} 
Inductive theory building \\
$\bullet \quad$ Validity \\
$\bullet$ & Reliability \\
\end{tabular} & $\begin{array}{l}\text { Dubé and Paré (2003) } \\
\text { Eisenhardt (1989) } \\
\text { Miles and Huberman (1994) }\end{array}$ \\
\hline “c” Grounded theory methodology & \begin{tabular}{|l} 
Inductive theory building \\
- $\quad$ Reliability of data \\
- Theoretical sampling procedures; \\
systematic coding; constant \\
comparative analysis \\
- $\quad$ Theoretical density
\end{tabular} & $\begin{array}{l}\text { Charmaz (2014) } \\
\text { Corbin and Strauss (2008) } \\
\text { Glaser and Strauss (1967) } \\
\text { Glaser (2005) } \\
\text { Strauss and Corbin (1998) } \\
\text { Urquhart et al. (2010) } \\
\end{array}$ \\
\hline “d” Exploratory case studies & $\begin{array}{|cl|}\text { Discovery / Presentation of situation } \\
\text { - } & \text { Rich description, confessions, } \\
& \text { authenticity, auditability } \\
\text { - } & \text { Reconciliation of polyphonic narrative } \\
\text { - } & \text { Member checking } \\
\end{array}$ & $\begin{array}{l}\text { Eisenhardt (1989) } \\
\text { Kirsch (1997) } \\
\text { Mingers (2003) } \\
\text { Yin (1994) }\end{array}$ \\
\hline $\begin{array}{l}\text { “e” Ethnography / Interpretive case } \\
\text { study (realist) }\end{array}$ & \begin{tabular}{|l} 
Elaboration \\
- Thick description \& insights \\
- $\quad$ Quality of the theoretical scaffolding \\
- Interaction between researcher and \\
- subject \\
- $\quad$ Sontextualization \\
\end{tabular} & $\begin{array}{l}\text { Agar (1986) } \\
\text { Klein and Myers (1999) } \\
\text { Harvey and Myers (1995) } \\
\text { Walsham (1995a) } \\
\text { Van Maanen (1988) }\end{array}$ \\
\hline $\begin{array}{l}\text { “f” Ethnography / Interpretive case } \\
\text { study (impressionist) }\end{array}$ & \begin{tabular}{|l} 
Revealing larger and less obvious truths or \\
enabling suppressed voices \\
- $\quad$ Evocative \\
- $\quad$ Contextualization \\
- $\quad$ Emotive appeal \\
- $\quad$ Transfightening \\
$\quad$ institutions \\
\end{tabular} & $\begin{array}{l}\text { Golden-Biddle and Locke (1993) } \\
\text { Geertz }(1973,1983) \\
\text { Prasad (1997) } \\
\text { Hine (2000) } \\
\text { Van Maanen (1988) }\end{array}$ \\
\hline $\begin{array}{l}\text { “g” Hermeneutics }{ }^{12} \text { (distantiated } \\
\text { text) }\end{array}$ & \begin{tabular}{|c|} 
Imaginative but “valid” reading of texts \\
- $\quad$ Penetration of text; creativity in \\
crafting interpretive guesses \\
- $\quad$ Quality of argumentation in validation \\
- $\quad$ Coherence of interpretations \\
- $\quad$ Principle of charity \\
\end{tabular} & $\begin{array}{l}\text { Boland (1991) } \\
\text { Butler (1998) } \\
\text { Gadamer (1977) } \\
\text { Lee (1994) } \\
\text { Myers (1995) } \\
\text { Ricoeur (1991) }\end{array}$ \\
\hline $\begin{array}{l}\text { "h” Hermeneutics (author- } \\
\text { intentional text) }\end{array}$ & $\begin{array}{l}\text { Uncovering truth or original intent } \\
\text { - } \quad \text { Demonstrated correspondence with } \\
\text { original intent or meaning } \\
\text { - } \quad \text { Established correspondence with the } \\
\text { authors' other texts or texts of the } \\
\text { same tradition } \\
\text { - Coherence of interpretations } \\
\text { - Hermeneutic circle }\end{array}$ & Hirsch (1967) \\
\hline
\end{tabular}

\footnotetext{
${ }^{12}$ Some of the criteria for $g$ and $h$ also draw on Alvesson \& Sköldberg (2009).
} 


\section{Discussions and Implications}

We believe the above discussion regarding firstgeneration qualitative approaches in our discipline points to important lessons which can shed light on how qualitative research within the IS discipline has evolved as well as additional lessons that might be passed on to emergent second-generation qualitative approaches.

The first lesson is that there is much variety in qualitative research, and, consequently, authors and evaluators need to enact the understanding that: (a) distinct qualitative genres exist; (b) each genre can be associated with different attributes of the four elements of a qualitative study (i.e., data, theory, analysis, and claims); and (c) evaluation criteria should also fit with the characteristics of the genre.

The second lesson is that we believe creating an awareness of different qualitative genres and their respective characteristics is useful for further development and maturation of qualitative research in the IS discipline. We encourage the following points to be kept in mind:

- Qualitative research can be successfully conducted from a data-centric perspective or an interpretation-centric perspective, by using either an inductive or a deductive approach, or some suitable combination (Figure 2a). However, it is essential that the researcher conduct his or her research according to a coherent set of relevant assumptions. Genres (or subgenres) capture these assumptions in a succinct manner, making the type of study, the built-in philosophical assumptions, and the criteria for evaluation evident to authors, reviewers, editors, and readers.

- Specifying the genre signals the type of criteria to use when judging a qualitative manuscript. While it is difficult to lay blame for the current state of internal incoherence on any one source, as Tables 1 reveals, manuscripts being subjected to bias and "prejudice" constitutes a systemic problem within the discipline that most likely resides among all involved stakeholders (authors, reviewers, and editors). We can say, with some level of certainty, that the recognition of and increased use of genres will lead to the maturation of the use of qualitative approaches. It will improve the overall quality and credibility of qualitative research while reducing the frustrations described earlier concerning reviewers misjudging manuscripts or imposing conflicting methodological demands. This is particularly important, as mixed method studies, with each method having a different set of underlying assumptions, have become popular in the discipline (Venkatesh et al., 2016).

- We reiterate that the identified genres are not the only legitimate ones that should guide research. There are many different types (genres) of qualitative research (Baskerville \& Myers, 2004; Williams \& Karahanna, 2013; Zachariadis, Scott, \& Barrett, 2013), and we present a subset here: those first-generation qualitative approaches that have been the most prevalent in the IS discipline over the years (Fig. 2). New genres or subgenres, such as discourse analysis, critical realist case study, and virtual ethnography, continue to be established. Further, for those who see genre as constraining the flexible and creative nature of qualitative work, we clarify that the boundaries of genres on our map are not set in stone and that we do not oppose the creation of new genres or even mixing genres, provided this is thoughtfully done. In other words, we suggest that research deviating from known genres be accompanied by pointed explanation and justification regarding how it treats the four elements of qualitative research, as well as guidance concerning the standards by which it should be judged.

There are some important ideas pertaining to the emergent next generation qualitative research approaches:

The need to acknowledge a variety of legitimate qualitative approaches will remain, and will probably intensify with the increasing pressure to embrace "big[ger] data," "computational," and "machine learning” approaches (e.g., Berente \& Seidel, 2014; Gaskin, Berente, Lyytinen, \& Yoo, 2014; Goes, 2013), often with codified metrics for rigor, into the world of qualitative research. While the value of these new innovations is unquestionable, it will be important for us to remind ourselves that such approaches that are typically data-centric and inductive (i.e. these approaches incorporate large amounts of data and process them using algorithmic repeatable processes to mine patterns), have specific underlying assumptions, and are not necessarily suited for all types of contributions that qualitative researchers seek to offer. In some cases, interpretation-centric work will need to be integrated with computational data-centric approaches (Berente \& Seidel, 2014). As a community, while welcoming new approaches, we must strive to preserve the value of appreciating qualitative research across the map, not just privileging the data-centric inductive variety that handles vast amounts of data in an algorithmic fashion.

Also, other second-generation approaches being introduced into the discipline, such as discourse analysis (e.g., Beaulieu, Sarker, \& Sarker, 2015; Miranda, Young, \& Yetgin, 2016), can expect to experience similar evolution to first-generation 
approaches like GTM or hermeneutics. The exact pattern cannot, of course, be forecast, but a scenario of the following sort could be considered illustrative. For example, after some initial resistance to the discourse analysis approach, an "anything goes" phase might take over, wherein discourse analysis would be indiscriminately and unreflectively mixed with concepts of conversational analysis, grounded theory approaches, and content analysis, whereupon the various traditions of discourse analysis (e.g. pragmatic, poststructuralist, and critical) would be indistinguishable as practiced in IS (e.g., Wood \& Kroger, 2000). Thereafter, the differences between the different approaches might become clear and the schools of thought on discourse analysis might split, though scholars from different schools would likely seek to dominate the research landscape by insisting on research being done in a specific (i.e., their) way, reminiscent of the "prejudice" Markus (1997) had alerted us to. Once maturation is reached in the community regarding discourse analysis, the researcher and the readers would be expected to be aligned in terms of methodological expectations, and the specific strand of discourse analysis recognized by both sides.

Meanwhile, evaluators, both reviewers and editors, will need to be proactively vigilant to ensure that as the research community evolves with respect to secondgeneration approaches, authors are not unfairly dismissed because of the lack of uniform or shared understanding of the given qualitative approach at a given time, or because the wrong criteria are imposed on it.

The value of viewing IS qualitative research through the lens of an evolution of an innovation is that it creates an understanding of how the current state of qualitative research came to be, as well as where it may be headed. And while some qualitative genres and communities may be reaching the maturation stage, new and innovative genres, such as critical realist studies, virtual ethnography, and the use of computation techniques, are percolating in the research community as they make their way through the evolutionary process. While each of these approaches will undoubtedly have their own challenges, we believe that they will continue to evolve in much the same way as the first-generation qualitative research approaches have. By looking at and consolidating lessons from the past, we may be able to avoid the same mistakes and manage the evolution of these emergent qualitative approaches more effectively.

\section{Conclusions}

In this editorial (Part 1), we offer a critical commentary on the arena of qualitative research in the IS discipline. We note that there are many facets of qualitative research, and we focus on methodological issues here. By reviewing four fundamental elements of qualitative research-namely, data, theory, analysis, and claims, and their diverse nature-we have argued that qualitative research is not a monolith but rather consists of different genres, each of which is associated with specific assumptions regarding the nature of these four elements. The practice of arbitrarily mixing criteria and references for methodological guidance and justification needs examination. Our intentions for this editorial include assisting the information systems field in taking a step forward not only to enhance awareness of genres, but also to enact awareness in our roles as authors, reviewers, and editors. This, we believe, will contribute to the further maturing of qualitative research in the IS discipline. Please stay tuned for Part 2 of the editorial in which we analyze articles for genre coherence from four leading mainstream IS journals of the discipline, and offer additional illustrations and implications regarding the practice of qualitative research in our discipline.

\section{Acknowledgements}

A preliminary version of this material was published in Proceedings of the $40^{\text {th }}$ Annual Hawaii International Conference on Systems Sciences (2007). The authors of the editorial are grateful to the senior editor, Carol Saunders, and to the many scholars who have offered feedback and/or encouragement, including (but not limited to) Niels-Bjorn Andersen, Kim Normann Andersen, David Avison, Michael Barrett, Nick Berente, Ann-Frances Cameron, Suranjan Chakraborty, Sutirtha Chatterjee, Jan Damsgaard, Yulin Fang, Walter Fernandez, Bob Galliers, Dirk Hovorka, Atreyi Kankanhalli, Elena Karahanna, Natalia Levina, Moez Limayem, Dorothy Leidner, Likoebe Maruping, Shaila Miranda, Jan Ondrus, Jeff Parsons, Arun Rai, Narayan Ramasubbu, Matti Rossi, Rajiv Sabherwal, Saonee Sarker, Daniel Schlagwein, Maung Sein, Virpi Tuunainen, Cathy Urquhart, V. Venkatesh, and Geoff Walsham. 


\section{References}

Abbasi, A., Sarker, S., \& Chiang, R. H. L. (2016). Big data research in information systems: toward an inclusive research agenda. Journal of the Association for Information Systems, 17(2), ixxxii.

Agar, M. H. (1986). Speaking of ethnography. Los Angeles, CA: SAGE.

Alvesson, M., \& Kärreman, D. (2007). Constructing mystery: Empirical matters in theory development. Academy of Management Review, 32(4), 1265-1281. Retrieved from https://doi.org/10.5465/AMR.2007.26586822

Alvesson, M., \& Sköldberg, K. (2009). Reflexive methodology: New vistas for qualitative research. Los Angeles, CA: SAGE.

Astley, W. G. (1985). Administrative science as socially constructed truth. Administrative Science Quarterly, 30(4), 497-513.

Atkinson, P., \& Hammersley, M. (1994). Ethnography and participant observation. In N. K. Denzin \& Y. S. Lincoln (Eds.), Handbook of Qualitative Research (pp. 248-261). Los Angeles, CA: SAGE.

Bansal, P. (Tima), \& Corley, K. (2011). From the editors: The coming of age for qualitative research: Embracing the diversity of qualitative methods. The Academy of Management Journal, 54(2), 233-237.

Barrett, M., \& Walsham, G. (2004). Making contributions from interpretive case studies: Examining processes of construction and use. In B. Kaplan, D. Truex, D. Wastell, A. T. Wood-Harper, \& J. I. DeGross (Eds.), Information Systems Research: Relevant Theory and Informed Practice (pp. 293-314). Boston, MA: Kluwer. Retrieved from https://www.infona.pl//resource/bwmeta1.elem ent.springer-12380402-9ccd-34c5-96d70c59f9bdb4f3

Baskerville, R., \& Myers, M. D. (2004). Special issue on action research in information systems: Making is research relevant to practice: Foreword, MIS Quarterly, 28(3), 329-335.

Beaulieu, T., Sarker, S., \& Sarker, S. (2015). Analyzing online discourse: Some theoretical ideas and a visualization approach. In International Conference on Information Systems 2015 Proceedings. Retrieved from https://aisel.aisnet.org/icis2015/proceedings/R esearchMethods/6
Benbasat, I., Goldstein, D. K., \& Mead, M. (1987). The case research strategy in studies of information systems. MIS Quarterly, 11(3), 369-386.

Berente, N., \& Seidel, S. (2014). Big data \& inductive theory development: Towards computational grounded theory? In Americas Conference on Information Systems 2014 Proceedings. Retrieved from https://aisel.aisnet.org/amcis2014/ResearchMe thods/GeneralPresentations/1

Berger, P., \& Luckmann, T. (1966). The Social Construction of Reality: A Treatise in the Sociology of Knowledge. New York, NY: Anchor.

Bernardi, R. (2017) Health information systems and accountability in Kenya: A structuration theory perspective. Journal of the Association for Information Systems, 18(12), 931-957.

Birks, D. F., Fernandez, W., Levina, N., \& Nasirin, S. (2013). Grounded theory method in information systems research: Its nature, diversity and opportunities. European Journal of Information Systems, 22(1), 1-8.

Boland, R. J. (1991). Information system use as a hermeneutic process. Amsterdam: Elsevier.

Bryant, A., \& Charmaz, K. (2007). The SAGE handbook of grounded theory. Los Angeles, CA: SAGE.

Butler, T. (1998). Towards a hermeneutic method for interpretive research in information systems. Journal of Information Technology, 13(4), 285300.

Campbell, K. K., \& Jamieson, K. H. (1978). Form and genre in rhetorical criticism: An introduction. In Form and genre: Shaping rhetorical action (pp. 9-32). Falls Church, VA: Speech Communication Association.

Charmaz, K. (2014). Constructing grounded theory: A practical guide through qualitative research. London: SAGE.

Conboy, K., Fitzgerald, G., \& Mathiassen, L. (2012). Qualitative methods research in information systems: Motivations, themes, and contributions. European Journal of Information Systems, 21(2), 113-118.

Corbin, J., \& Strauss (2008). Basics of qualitative research: Techniques and procedures for developing grounded theory ( 3rd ed.). Los Angeles, CA: SAGE.

Creswell, J. W. (1998). Qualitative inquiry and research design: Choosing among five traditions. Los Angeles, CA: SAGE. 
Deetz, S. (1996). Crossroads: Describing differences in approaches to organization science: Rethinking burrell and morgan and their legacy. Organization Science, 7(2), 191-207.

Denzin, N. K., \& Lincoln, Y. S. (2000). Handbook of qualitative research (Vol. 2nd). Los Angeles, CA: SAGE.

Dibbern, J., Winkler, J., \& Heinzl, A. (2008). Explaining variations in client extra costs between software projects offshored to India. MIS Quarterly, 32(2), 333-366.

DiMaggio, P. J. (1995). Comments on "What Theory is Not." Administrative Science Quarterly, 40(3), 391-397.

Doty, D. H., \& Glick, W. H. (1994). Typologies as a unique form of theory building: Toward improved understanding and modeling. Academy of Management Review, 19(2), 230251.

Dubé, L., \& Paré, G. (2003). Rigor in information systems positivist case research: Current practices, trends, and recommendations. MIS Quarterly, 27(4), 597-636.

Eisenhardt, K. M. (1989). Building theories from case study research. The Academy of Management Review, 14(4), 532-550.

Fitzgerald, B., \& Howcroft, D. (1998). Towards dissolution of the is research debate: From polarization to polarity. Journal of Information Technology, 13(4), 313-326.

Flyvbjerg, B. (2006). Five misunderstandings about case-study research. Qualitative Inquiry, 12(2), 219-245.

Fontana, A., \& Frey, H. J. (2000). The interview: From structured questions to negotiated text (2nd ed., pp. 645-672). Los Angeles, CA: SAGE.

Gadamer, H.-G. (1977). Philosophical hermeneutics. Berkeley: University of California Press.

Gadamer, H.-G. 1989. Truth and Method (2nd rev. ed.). New York, NY: Continuum.

Gadamer, H.G. 2001. Gadamer in conversation: reflections and commentary (Ed. and Trans. R. E. Palmer). New Haven, CT: Yale University Press.

Galliers, R. D., \& Land, F. F. (1987). Viewpoint: Choosing appropriate information systems research methodologies. Communications of the ACM, 30(11), 901-902.

Gaskin, J., Berente, N., Lyytinen, K., \& Yoo, Y. (2014). Toward generalizable sociomaterial inquiry: A computational approach for zooming in and out of sociomaterial routines. MIS Quarterly, 38(3), 849-871.

Geertz, C. (1973). The interpretation of cultures: Selected essays. New York, NY: Basic .

Geertz, C. (1983). Local knowledge: Further essays in interpretive anthropology. New York, NY: Basic.

Gibson, C. F., \& Nolan, R. L. (1974). Managing the four stages of EDP growth. Harvard Business Review, 52(1), 76-87.

Glaser, B. G., \& Strauss, A. L. (1967). The discovery of grounded theory: Strategies for qualitative research. New Brunswick, NJ: AldineTransaction. Retrieved from http://books.google.com/books?hl=en\&lr=\&id $=$ rtiNK68Xt08C\&oi=fnd \&pg=PA1\&dq=glaser +strauss\&ots=UUARVhWFZM\&sig=FB0KF XUCMYk80jBqLZ0x1pIxH84

Goes, P. B. (2013). Editor's comments: Commonalities across is silos and intradisciplinary information systems research. MIS Quarterly, 37(2), iii-vii.

Golden-Biddle, K., \& Locke, K. (1993). Appealing work: An investigation of how ethnographic texts convince. Organization Science, 4(4), 595-616.

Gregor, S. (2006). The nature of theory in information systems. MIS Quarterly, 30(3), 611-642.

Grondin, J. (1997). Introduction to philosophical hermeneutics. New Haven, CT: Yale University Press.

Gubrium, J. F., \& Holstein, J. A. (1997). The New language of qualitative method. New York, NY: Oxford University Press.

Hammersley, M. (2008). Questioning qualitative inquiry: Critical essays. Los Angeles, CA: SAGE.

Harrington, A. (2005). Modern social theory. New York, NY: Oxford University Press. Retrieved from

http://www.csun.edu/ snk1966/Harrington.pdf

Harvey, L. (1997). A discourse on ethnography. London: Chapman \& Hall. Retrieved from http://www.google.com/books?hl=en\&lr=\&id $=$ YqFJkwgx7MAC\&oi $=$ fnd \&pg $=$ PA207\&dq $=$ A+Discourse+on+Ethnography\&ots=ZRSJPcq Ejg\&sig=d0UfCmdUAKALKGJFkB04B1xYfA

Harvey, L. J., \& Myers, M. D. (1995). Scholarship and practice: The contribution of ethnographic research methods to bridging the gap. Information Technology \& People, 8(3), 13-27. 
Henfridsson, O. (2014). The power of an intellectual account: Developing stories of the digital age. Journal of Information Technology, 29(4), 356-357.

Hine, C. (2000). Virtual ethnography. Los Angeles, CA: SAGE.

Hirsch, E. D. (1967). Validity in interpretation (Vol. 260). New Haven, CT: Yale University Press. Retrieved from http://books.google.com/books?hl=en\&lr=\&id $=$ CcjUGVlekQQC\&oi $=$ fnd\&pg $=$ PR7\&dq $=$ hirs ch+1967\&ots=B2fmN3hUP7\&sig=o6n_F9HU S3MI7YBMH497-mfrvSQ

Hirschheim, R. A. (1992). Information systems epistemology: An historical perspective. In Information systems research: Issues, methods and practical guidelines (pp. 28-60). Oxford, UK: Blackwell.

Holeman, I. and Barrett, M. (2017). Insights from an ICT4D initiative in Kenya's immunization program: Designing for the emergence of sociomaterial practices. Journal of the Association for Information Systems, 18(12), 900-930.

Holstein, J. A., \& Gubrium, J. F. (1995). The active interview. Los Angeles, CA: SAGE.

Kirsch, L. S. (1997). Portfolios of control modes and is project management. Information Systems Research, 8(3), 215-239.

Klein, H. K., \& Myers, M. D. (1999). A set of principles for conducting and evaluating interpretive field studies in information systems. MIS Quarterly, 23(1), 67-93.

Kozinets, R. V. (2002). The field behind the screen: Using netnography for marketing research in online communities. Journal of Marketing Research, 39(1), 61-72.

Lee, A. S. (1989). A scientific methodology for MIS case studies. MIS Quarterly, 13(1), 33-50.

Lee, A. S. (1991). Integrating positivist and interpretive approaches to organizational research. Organization Science, 2(4), 342-365.

Lee, A. S. (1994). Electronic mail as a medium for rich communication: An empirical investigation using hermeneutic interpretation. MIS Quarterly, 18(2), 143-157.

Lee, A., \& Sarker, S. (2008). A schema for relating and combining quantitative, qualitative, positivist, and interpretive research methods in the discipline of information systems. Unpublished Manuscript, IS Department, London School of Economics.
Leidner, D. E. (2018). Review and theory symbiosis: An introspective retrospective. Journal of the Association for Information Systems, 19(6), 552-567.

Markus, M. L. (1983). Power, politics, and MIS implementation. Communications of the ACM, 26(6), 430-444.

Markus, M. L. (1997). The qualitative difference in information systems research and practice. In Proceedings of the IFIP TC8 WG 8.2 International Conference on Information systems and Qualitative Research (pp. 11-27). ACM

Miles, M. B., \& Huberman, A. M. (1984). Qualitative data analysis: a soucebook of new methods. Los Angeles, CA: SAGE.

Miles, M. B., \& Huberman, A. M. (1994). Qualitative Data Analysis: An expanded sourcebook. Los Angeles, CA: SAGE.

Mingers, J. (2003). The Paucity of multimethod research: A review of the information systems literature. Information Systems Journal, 13(3), 233-249.

Mintzberg, H. (2005). Developing theory about the development of theory. In Great minds in management: The process of theory development (pp. 355-372). Oxford, UK: Oxford University Press. Retrieved from http://intranet.catie.ac.cr/intranet/posgrado/poli tica_gober/ANTERIOR/2008/Modulo\%201b/ UICN/An\%C3\%A1lisis\%20estrat\%C3\%A9gic o/Mintzberg/devtheory.pdf

Miranda, S., Young, A., \& Yetgin, E. (2016). Are social media emancipatory or hegemonic? Societal effects of mass media digitization in the case of the SOPA discourse. MIS Quarterly, 40(2), 303-329.

Molnar, W., Nandhakumar, J., and Stacey, P. (2017). A paradox of progressive saturation: The changing nature of improvisation over time in a systems development project. Journal of the Association for Information Systems, 18(11), 814-836.

Myers, M. D. (2016). Hermeneutics in organization studies. In R. Mir, H. Willmott, \& $\mathrm{M}$. Greenwood (Eds.), The Routledge companion to philosophy in organization studies (pp. 113124). New York, NY: Routledge.

Myers, M. D. (1995). Dialectical hermeneutics: A theoretical framework for the implementation of information systems. Information Systems Journal, 5(1), 51-70. 
Myers, M. D., \& Avison, D. (2002). An introduction to qualitative research in information systems. In Qualitative research in information systems: A reader (pp. 3-12). Los Angeles, CA: SAGE. Retrieved

from https://eprints.soton.ac.uk/35818/

Patton, M. Q. (1990). Qualitative evaluation and research methods (2nd ed.). Los Angeles, CA: SAGE.

Phillips, N., \& Brown, J. L. (1993). Analyzing communication in and around organizations: A critical hermeneutic approach. Academy of Management Journal, 36(6), 1547-1576.

Prasad, A. (2002). The contest over meaning: hermeneutics as an interpretive methodology for understanding texts. Organizational Research Methods, 5(1), 12-33.

Prasad, P. (1997). Systems of meaning: Ethnography as a methodology for the study of information technologies. In Information Systems and Qualitative Research (pp. 101-118). Boston, MA: Springer. Retrieved from https://link.springer.com/chapter/10.1007/9780-387-35309-8_7

Reichertz, J. (2007). Abduction: The logic of discovery of grounded theory. In A. Bryant \& K. C. Charmaz (Eds.), Handbook of grounded theory (pp. 214-228). London: SAGE. Retrieved from http://nbn-resolving.de/urn:nbn:de:0168-ssoar13172

Ricoeur, P. (1991). From text to action (Vol. 2). Evanston, IL: Northwestern University Press.

Robey, D. (1996). Research commentary: diversity in information systems research: Threat, promise, and responsibility. Information Systems Research, 7(4), 400-408.

Saldaña, J. (2012). The coding manual for qualitative researchers. Los Angeles, CA: SAGE. Retrieved from http://www.google.com/books?hl=en\&lr=\&id $=\mathrm{kUms8Q}$ rE_SAC\&oi=fnd\&pg=PP2\&dq=The +Coding+Manual+for+Qualitative+Researcher s\&ots=zJmYDIAtz8\&sig=huH8IZhzPo3uSRr hFn_WhZBGdAw

Sarker, S., Chakraborty, S., Tansuhaj, P. S., Mulder, M., \& Dogerlioglu-Demir, K. (2013). The "mail-order-bride" (MOB) phenomenon in cyberworld: An interpretive investigation. ACM Transactions on Management Information Systems, 4(3), 10:1-10:36. https://doi.org/10.1145/2524263

Sarker, S., \& Lee, A. S. (2006). Does the use of computer-based BPC tools contribute to redesign effectiveness? Insights from a hermeneutic study. IEEE Transactions on Engineering Management, 53(1), 130-145.

Sarker, S., Xiao, X., \& Beaulieu, T. (2013). Guest editorial: Qualitative studies in information systems: A critical review and some guiding principles. MIS Quarterly, 37(4), iii-xviii.

Schultze, U., \& Avital, M. (2011). Designing interviews to generate rich data for information systems research. Information and Organization, 21(1), 1-16.

Schweizer, T. (1998). Epistemology: The nature and validation of anthropological knowledge. In $\mathrm{H}$. R. Bernard (Ed), Handbook of Methods in Cultural Anthropology (pp. 39-87). Lanham, MD:AltaMira.

Seidel, S. and Urquhart, C. (2013). On emergence and forcing in information systems grounded theory studies: The case of Strauss and Corbin. Journal of Information Technology, 28(3), pp.237-260.

Silverman, D. (2001). Interpreting qualitative data: methods for analysing talk, text and interaction. London: SAGE.

Smith, J. K. (1993). Hermeneutics and qualitative inquiry. In D. J. Flinders, \& G. E. Mills (Eds.), Theory and concepts in qualitative research: perspectives from the field (pp. 183-200). New York, NY: Teachers College Press.

Strauss, A., \& Corbin, J. M. (1998). Basics of qualitative research: Techniques and procedures for developing grounded theory. Los Angeles, CA: SAGE.

Su, N. (2015). Cultural sensemaking in offshore information technology service suppliers: A cultural frame perspective. MIS Quarterly, 39(4), 959-984.

Sutton, R. I., \& Staw, B. M. (1995). What theory is not. Administrative Science Quarterly, 40(3), 371384.

Thomas, J. (1993). Doing Critical Ethnography. Los Angeles, CA: SAGE.

Trauth, E., \& Jessup, L. (2000). Understanding computer-mediated discussions: Positivist and interpretive analyses of group support system use. MIS Quarterly, 24(1), 43-79.

Travers, M. (2001). Qualitative research through case studies. Los Angeles, CA: SAGE.

Urquhart, C., Lehmann, H., \& Myers, M. D. (2010). Putting the "theory" back into grounded theory: Guidelines for grounded theory studies in 
information systems. Information Systems Journal, 20(4), 357-381.

Vaast, E., Davidson, E. J., \& Mattson, T. (2013). Talking about technology: The emergence of a new actor category through new media. MIS Quarterly, 37(4), 1069-1092.

Vaast, E., \& Walsham, G. (2013). Grounded theorizing for electronically mediated social contexts. European Journal of Information Systems, 22(1), 9-25.

Van De Ven, A. H. (2007). Engaged scholarship: A guide for organizational and social research. Oxford, UK: Oxford University Press.

Van Maanen, J. (1988). Tales of the field: On writing ethnography. Chicago, IL: University of Chicago Press.

Van Maanen, J., Sørensen, J. B., \& Mitchell, T. R. (2007). The interplay between theory and method. Academy of Management Review, 32(4), 1145-1154.

Venkatesh, V., Brown, S., \& Sullivan, Y. (2016). Guidelines for conducting mixed-methods research: An extension and illustration. Journal of the Association for Information Systems, 17(7), 435-495.

Walsham, G. (1993). Interpreting information systems in organizations (1st ed.). New York, NY: John Wiley \& Sons.

Walsham, G. (1995a). Interpretive case studies in IS research: Nature and method. European Journal of Information Systems, 4(2), 74-81.

Walsham, G. (1995b). The emergence of interpretivism in IS research. Information Systems Research, 6(4), 376-394.
Walsham, G. (2006). Doing interpretive research. European Journal of Information Systems, 15(3), 320-330.

Walsham, G., \& Sahay, S. (1999). GIS for districtlevel administration in India: Problems and opportunities. MIS Quarterly, 23(1), 39-65.

Walsh, I., Holton, J. A., Bailyn, L., Fernandez, W., Levina, N., \& Glaser, B. (2015). What grounded theory is . . . A critically reflective conversation among scholars. Organizational Research Methods, 18(4), 581-599.

Weber, R. (2012). Evaluating and developing theories in the information systems discipline. Journal of the Association for Information Systems, 13(1), 1-30.

Weick, K. E. (1995). What theory is not, theorizing is. Administrative Science Quarterly, 40(3), 385390.

Williams, C. K., \& Karahanna, E. (2013). Causal explanation in the coordinating process: A critical realist case study of federated it governance structures. MIS Quarterly, 37(3), 933-964.

Wood, L. A., \& Kroger, D. R. O. (2000). Doing discourse analysis: Methods for studying action in talk and text. Los Angeles, CA: SAGE.

Yin, R. K. (1993). Applications of case study research. Los Angeles, CA: SAGE.

Yin, R. K. (1994). Case study research: Design and methods. Los Angeles, CA: SAGE.

Zachariadis, M., Scott, S., \& Barrett, M. (2013). Methodological implications of critical realism for mixed-methods research. MIS Quarterly, 37(3), 855-879. 


\section{About the Authors}

Suprateek Sarker (“Supra”) is Rolls-Royce Commonwealth Commerce Professor (information technology) at the University of Virginia’s McIntire School of Commerce. His research, which is largely qualitative in nature, has been published in leadng journals. He serves or has served on a number of editorial boards, including MIS Quarterly (as former senior editor), Journal of Management Information Systems (on the board of editors), Decision Sciences Journal (as former senior editor) Information Technology \& People, IEEE Transactions on Engineering Management, Journal of Information Technology Case and Application Research (as former editor in chief) and the Journal of the Association for Information Systems (as the current editor in chief). In 2006, he was a corecipient of the Stafford Beer Medal from the Operational Research Society (United Kingdom); in 2016, he was awarded an honorary doctorate by the Faculty of Information Technology, University of Jyväskylä (Finland); in 2017, he was named a fellow of the Association for Information Systems; and in April 2018, he was named distinguished alumnus of Operations, Business Analytics, and Information Systems Department, University of Cincinnati, where he completed his PhD studies in 1997, under Prof. Allen S. Lee.

Xiao Xiao is an associate professor at Copenhagen Business School, Department of Digitalization. She received her $\mathrm{PhD}$ in information systems from Washington State University. Her main research areas include IT servitization (with the specific instance of cloud computing), ICT in emerging economies with a specific focus on digital commerce in China, qualitative research methodologies, and sports digitalization. Her research has appeared in premier IS journals such as MIS Quarterly, Journal of Information Technology, Information and Management, and MIS Quarterly Executive, as well as in conference proceedings such as the International Conference on Information Systems.

Tanya Beaulieu is an assistant professor at Utah State University, Jon M. Huntsman School of Business. She received her $\mathrm{PhD}$ in management information systems from Washington State University. Her research interests include communication in online communities, crowdfunding, and entrepreneur's use of technology. She has published in outlets such as MIS Quarterly, Communications of the Association for Information Systems, and the Journal of Computer Information Systems, as well as in proceedings such as the International Conference of Information Systems. She is currently serving as an associate editor for the Communications of the Association for Information Systems. Prior to completing her PhD, Dr. Beaulieu owned a software development and consulting firm specializing in custom software development for large enterprise systems.

Allen S. Lee is professor emeritus of information systems at Virginia Commonwealth University. He served as associate dean at both Virginia Commonwealth University and McGill University, as editor in chief of MIS Quarterly, and as a founding senior editor of MIS Quarterly Executive. His research program has involved identifying basic lessons from thes philosophy and history of science and extending them in the information systems discipline to show not only how qualitative research can be done rigorously, but also how quantitative research equally needs to live up to the requirements of science. He is a fellow of the Association for Information Systems, a member of the Circle of Compadres of the Information Systems Doctoral Students Association of the KPMG PhD Project, and a founder of Chinese American Professors of Information Systems. In 2015, he received the LEO Award for "lifetime exceptional achievement in information systems" from the Association for Information Systems.

Copyright (C 2018 by the Association for Information Systems. Permission to make digital or hard copies of all or part of this work for personal or classroom use is granted without fee provided that copies are not made or distributed for profit or commercial advantage and that copies bear this notice and full citation on the first page. Copyright for components of this work owned by others than the Association for Information Systems must be honored.

Abstracting with credit is permitted. To copy otherwise, to republish, to post on servers, or to redistribute to lists requires prior specific permission and/or fee. Request permission to publish from: AIS Administrative Office, P.O. Box 2712 Atlanta, GA, 30301-2712 Attn: Reprints, or via email from publications@aisnet.org. 